\title{
Screening for preeclampsia by urine albumin to creatinine ratio
}

\author{
Anupma Upadhyay, Meena Dayal \\ Correspondence: Dr Anupma Upadhyay, Assistant Professor, Department of Obstetrics \\ and Gynaecology, GMC Banda, UP, India; Email - dr.anu.ald@gmail.com \\ Distributed under Creative Commons Attribution-Share Alike 4.0 International.
}

\begin{abstract}
$\underline{\text { ABSTRACT }}$
Background: Proteinuria is a major component of preeclampsia. Urine protein measurement after 24 hour urine collection is the traditional standard method for the detection of proteinuria. It is time consuming. As an alternative, random spot sampling for a urine protein to creatinine ratio has been investigated. Objective: Screening for preeclampsia by urine albumin to creatinine ratio. Methods: The study was conducted on 202 antenatal women with gestational age 16-18 weeks. Specimens for measuring protein to creatinine ratio are obtained. Urine albumin was estimated by Bromocresol green assay and urine creatinine level was estimated by modified Jaff's reaction. Urinary albumin to creatinine ratio of 0.2 or more was considered to be abnormal. Results: Out of 202 women 30 women had urine albumin creatinine ratio $>0.2$ and $12(40 \%)$ developed preeclampsia while out of 160 women with urine albumin to creatinine ratio $<0.2$ only $4(2.5 \%)$ developed preeclampsia. The sensitivity, specificity, positive predictive value and negative predictive value of the test were 75\%, 89.6\%, 40\% and $97.5 \%$ respectively. Conclusion: Spot urinary albumin to creatinine ratio is a reasonable rule out test for significant proteinuria. The Albumin to creatinine ratio is highly predictive to detect proteinuria and can be used as a rapid alternative test.
\end{abstract}

Keywords: Preeclampsia, proteinuria, albumin, creatinine.

Preeclampsia is a pregnancy specific multisystem disorder of unknown etiology that is characterized by development of hypertension and proteinuria after 20 weeks of gestation. Preeclampsia is regarded as severe if hypertension is accompanied by massive proteinuria $\left(>5 \mathrm{~g} /\right.$ day) ${ }^{1}$. An increase in total protein or albumin excretion is considered to be a sign of aggravation of preeclampsia, reflecting severe nephropathy. The 24 hours urine collection for protein is the gold standard in the diagnosis of preeclampsia. ${ }^{2}$ This method is time consuming, inconvenient and results may be inaccurate hence collection of urine is missed, depending upon the individual. An alternative method is to use the random albumin creatinine ratio. The protein to creatinine ratio of a single urine sample correlates with 24 hours protein excretion. In the presence of a stable glomerular filtration rate, urinary creatinine is excreted at a fairly constant rate $^{3}$, which makes it useful as an internal reference. The usefulness of this method for assessing proteinuria in a non pregnant population is substantiated in the literature ${ }^{4}$. The international society for study of hypertension in pregnancy (ISSHP) has accepted spot urine protein to creatinine ratio as a method for identification of significant proteinuria (>300 mg in 24 hours). ${ }^{5}$ A protein

Received: 9 th October 2017. Accepted: 30 th November 2017.

Upadhyay A, Dayal M. Screening for preeclampsia by urine albumin to creatinine ratio. The New Indian Journal of OBGYN. 2018; 4(2): $117-20$. 
to creatinine ratio of $<0.2$ rules out significant proteinuria. The aim of this study is to observe urine albumin to creatinine ratio in preeclampsia.

\section{Method}

The study was done on 202 antenatal women between 16-18 weeks of gestation in M.L.N. Medical College. The study was certified by local ethics committee and informed valid consent was obtained from the participants. A detailed clinical history was taken and thorough clinical examination was done. Women with history of diabetes, chronic nephritis, essential hypertension, steroid use and collagen vascular diseases were excluded from the study. Apart from routine antenatal investigations urine albumin and creatinine ratio was done. Spot midstream urine specimen as obtained. Urinary albumin was estimated by Bromocresol green assay. This assay is based on the principle that at $\mathrm{pH} 3.68$ albumin acts as a cation and binds to the anionic dye Bromocresolgreen forming a green coloured complex. The absorbance of final colour is measured at $630 \mathrm{~nm}$. The colour intensity of the complex is proportional to albumin concentration in the sample.

Albumin $(\mathrm{g} / \mathrm{dl})=($ Absorbance of test $/$ Absorbance of standard) $\times 4$

Creatinine level was estimated by modified Jaff's reaction. Creatinine reacts with picric acid in an alkaline medium to form an orange coloured complex. The rate of formation of this complex is measured by reading the change in absorbance at $505 \mathrm{~nm}$ in a selected interval of time and is proportional to the concentration of creatinine.

Creatinine $(\mathrm{mg} / \mathrm{dl})=\left(\mathrm{AT}_{2}-\mathrm{AT}_{1} / \mathrm{AS}_{2}-\mathrm{AS}_{1}\right) \mathrm{x}$ dilution factor

$\mathrm{AT}_{1}=$ Initial absorbance of test; $\mathrm{AT}_{2}=$ Final absorbance of test; $\mathrm{AS}_{1}=$ Initial absorbance of standard and $\mathrm{AS}_{2}=$ Final absorbance of standard.

An urine albumin and creatinine ratio of $>0.2$ was taken as abnormal. All cases were followed throughout pregnancy and monitored for development of preeclampsia. The performance of spot urine albumin to creatinine ratio in predicting proteinuria as calculated in terms of sensitivity, specificity, positive predictive value and negative predictive value.

\section{Results}

Out of 202 women, 30 showed albumin creatinine ratio $>0.2$ and $12(40 \%)$ developed preeclampsia whereas

Table 1: Distribution of women according to Urine albumin creatinine ratio

\begin{tabular}{ll}
\hline Urine albumin creatinine ratio & No. of cases $(\%)$ \\
\hline$>0.2$ & $30(15.8 \%)$ \\
$<0.2$ & $160(84.2 \%)$ \\
Total & $190(100 \%)$ \\
\hline
\end{tabular}

out of 16 women who had albumin creatinine ratio $<0.2$ only $4(25 \%)$ developed preeclampsia while majority 156 $(97.5 \%)$ remained normotensive (Table 1 \& 2). Urine

Table 2: Urine Albumin creatinine Ratio in prediction of Preeclampsia

\begin{tabular}{|c|c|c|c|c|c|c|}
\hline 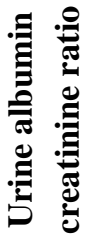 & 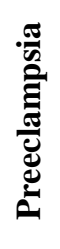 & 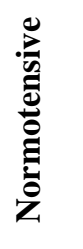 & 苞 & 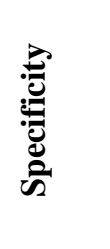 & 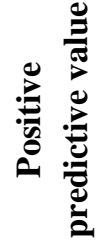 & 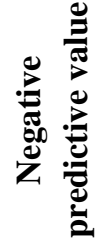 \\
\hline$>0.2$ & 12 & 30 & $75 \%$ & $89.6 \%$ & $40 \%$ & $97.5 \%$ \\
\hline$<0.2$ & 4 & 160 & & & & \\
\hline Total & 16 & 190 & & & & \\
\hline
\end{tabular}

albumin and creatinine ratio in a random sample had sensitivity $75 \%$, specificity $89.6 \%$, positive predictive value $40 \%$, and negative predictive value $97.5 \%$ in
Table 3: Predictive value of urine albumin creatinine ratio in various studies

\begin{tabular}{|c|c|c|c|c|}
\hline Studies & Sensitivity & Specificity & $\begin{array}{c}\text { Positive } \\
\text { Predictive } \\
\text { Value } \\
\end{array}$ & $\begin{array}{c}\text { Negative } \\
\text { Predictive } \\
\text { Value } \\
\end{array}$ \\
\hline Oscar et al $(1990)^{16}$ & $92 \%$ & $90 \%$ & $88.4 \%$ & $93.3 \%$ \\
\hline Robert et al (1990) ${ }^{12}$ & $93 \%$ & $90 \%$ & $87 \%$ & $95 \%$ \\
\hline Rodrigues et al (2001) ${ }^{13}$ & $90 \%$ & $70 \%$ & $88 \%$ & $92 \%$ \\
\hline Price CP et al $(2005)^{2}$ & $64 \%$ & $84 \%$ & $73 \%$ & $94 \%$ \\
\hline Papana et al (2005) ${ }^{14}$ & $81-98 \%$ & $52-99 \%$ & $40-92 \%$ & $90-98 \%$ \\
\hline $\begin{array}{l}\text { Result of studies from } \\
(1966-2007)\end{array}$ & & & & \\
\hline Present Study & $75 \%$ & $84 \%$ & $40 \%$ & $97.5 \%$ \\
\hline
\end{tabular}


prediction of preeclampsia.

\section{Discussion}

Proteinuria is one of the diagnostic criteria of preeclampsia. The gold standard method of 24 hours urine protein estimation is cumbersome and time consuming. Dipstick method of evaluating proteinuria is not perfectly correlated. With negative to trace dipstick results; $66 \%$ women will have proteinuria $>300 \mathrm{mg}$ in 24 hours. The protein to creatinine ratio of a single urine sample correlates significantly $(\mathrm{p}<0.001)$ with 24 hour protein excretion (Risberg et al) ${ }^{6}$. In the study by Demirci $\mathrm{O}$ et $\mathrm{al}^{7}$ (2014) protein to creatinine ratio had a good correlation with 24 hour protein excretion $\left(r^{2}: 0.758\right)$ in agreement with other studies ${ }^{8-11}$. In accordance with the present study Robert et al ${ }^{12}$, Rodrigues et al $^{13}$, Papanna et $\mathrm{al}^{14}$ have sown high sensitivity, specificity and negative predictive value but in contrast to the low positive predictive value of the test $(40 \%)$ detected in present study; they had shown a high positive predictive value for the test (Table 3 ). In the study by A K Wikstrom (2006) ${ }^{15}$ significant relationship as identified $\mathrm{p}<0.01$ between random albumin creatinine ratio and 24 hour urine albumin level but correlation was poor with pearson correlation coefficient of $0.65\left(\mathrm{r}^{2}: 0.42\right)$ but adjustment for maternal age and nifedipine medication significantly improved the correlation $\left(\mathrm{r}^{2}: 0.60\right)$. In the ISSHP statement for classification and diagnosis of hypertensive disorders of pregnancy, random protein to creatinine ratio is claimed to be equivalent to total protein excretion in a 24 hour sample for diagnosing significant proteinuria. Also according to BJOG (2011), in early second trimester albumin to creatinine ratio predicted preeclampsia quite before the onset of clinical manifestations.

\section{Conclusion}

Determination of random protein to creatinine ratio could replace 24 hours urine collection as a simpler, faster method for the diagnosis of significant proteinuria and screening for preeclampsia.

Conflict of interest: None. Disclaimer: Nil.

\section{References}

1.Sibai BM. Diagnosis and management of gestational hypertension and preeclampsia. Obstet Gynecol. 2003; 102: 181-92.

2.Price CP, Neall RG, Boyd JC. Use of protein : creatinine ratio measurements on random urine samples for prediction of significant proteinuria : a systematic review. Clin Chem. 2005; 51: 1577-86.

3.Vestergaard P, Leverett R. Constancy of urinary creatinine excretion. J Lab Clin Med. 1958; 51: 211-18.

4.Schab SJ, Christensen RL, Dougherty K, Klahr S. Quantitation of proteinuria by the use of protein to creatinine ratios in single urine samples. Arch intern Med. 1987; 147: 943-4.

5.Bron MA, Lindheimer MD, de Seit M, Van Assche A, Moutquin JM. The classification and diagnosis of the hypertensive disorders of pregnancy : statement from the international society for the study of hypertension in pregnancy(ISSHP). Hypertens Pregnancy. 2001; 20: IXXIV.

6.Risberg A, Larssen A, L yrenas S, Sjoquist M. Relationship between urinary albumin and albumin creatinine ratio during normal pregnanacy and preeclampsia. Scand J Clin Lab Invest. 2004; 64(1):17-23.

7.Demirci O, Kumru P, Arinkan A, Ardic C, Ansoy R, Tozkir E, et al. Spot Protein/Creatinine Ratio in Preeclampsia as an Alternative for 24-Hour Urine Protein. Balkan Med J. 2015 Jan; 32(1): 51-5.

8. Wheeler TL 2 nd, Blackhurst D, Dellinger EH, Ramsey PS. Usage of spot urine protein to creatinine ratios in the evaluation of preeclampsia. Am J Obstet Gynecol.2007;196:465 e1-4(Pubmed).

9.Rizk DE, Agrawal MM, Pathan JY, Obineche EN. Predicting proteinuria in hypertensive pregnancies with urinary protein to creatinine or calcium-creatinine ratio. $\mathrm{J}$ Perinatol. 2007; 27: 272-7. (Pubmed)

10.Shahbazian N, Hosseini-Asl F. A comparison of spot urine protein-creatinine ratio with 24 hour urine protein excretion in women with preeclampsia. Iran J Kidney Dis. 2008; 2: 127-31. (Pubmed)

11.Eslamian L, Behnam F, Tehrani ZF, Jamal A, Marsoosi $\mathrm{V}$. Random urine protein creatinine ratio as a preadmission test in hypertensive pregnancies. Acta Med Iran. 2011; 49: 81-4.

12.Robert M, Sepandj F, Dooley KC, Liston RM. Random protein creatinine ratio for the quantitation of proteinuria in pregnancy. Am J. Obstet gynecol. 1997; 90: 893(Pubmed) 
The New Indian Journal of OBGYN. 2018 (January-June); 4(2)

13.Rodrigues $\mathrm{MH}$. Calcium/creatinine ratio and microalbuminuria in prediction of PIH. Am .J. Obstet Gynecol.1988;159:1457-65.

14.Papana R, Mann LK, Kouides RW, Glantz JC.

Protein/creatinine in preeclampsia:a systematic review. Obstet Gynecol. 2008;112:135-44. (PubMed)

15.Wikström AK, Wikström J, Larsson A, Olovsson M. Random albumin/creatinine ratio for quantification of proteinuria in manifest pre-eclampsia. BJOG. 2006 Aug;113 (8):930-4. Epub 2006 Jul 7.

16.Oscar JE, Ron RP, Amos S, HilkiahuZB, Stephan G; Protein/Creatinine Ratio in Random Urine Specimens for
Quantitation of Proteinuria in Preeclampsia. The American College of Obstetricians and Gynecologists, 1990; 75(4): 604.

\section{Anupma Upadhyay ${ }^{1}$, Meena Dayal ${ }^{2}$}

${ }^{1}$ Assistant Professor, Department of Obstetrics and Gynaecology, GMC Banda, UP, India; ${ }^{2}$ Professor and Ex HOD MLN Medical College, Department of Obstetrics and Gynaecology, Allahabad, UP, India. 